\title{
Nutritional characteristics and consumer acceptability of sausages with different combinations of goat and beef meats
}

\author{
*Fatemeh Malekian, Margarita Khachaturyan, Sebhatu Gebrelul, and James F. \\ Henson
}

Southern University Agricultural Research and Extension Center, A. O. Williams Hall, P. O. Box 10010, Baton Rouge, Louisiana 70813, USA

*Corresponding author: Fatemeh Malekian, Professor, Southern University Agricultural Research and Extension Center, 181 B.A. Little Drive, A.O. Williams Hall, P.O. Box 10010, Baton Rouge LA 70813, USA

Submission date: October 28, 2015, Acceptance date: January 28, 2016: Publication date: January 29, 2016

\begin{abstract}
Background: Obesity and cardiovascular heart diseases are becoming more prevalent in the United States. This is partly due to the increasing consumption of red meats, such as pork and beef. However, goat meat has the potential to replace these traditionally consumed meats. Rice bran is a rich source of antioxidants, including vitamin $\mathrm{E}$, which can be utilized as a binder in meat and meat-related products.
\end{abstract}

Methods: Goat meat/beef sausages were formulated to contain either 50/50, 75/25 or 100/0 percent goat meat/beef, with either no added rice bran (NRB) or 3 percent stabilized rice bran (RB). Proximate analysis, fatty acids, $\alpha$-tocopherol and cholesterol concentrations of the six cooked formulations were determined. The six sausage formulations were compared in a consumer acceptability taste test.

Results: The fat concentration of the NRB and RB formulations decreased linearly with increasing percentages of goat meat $(\mathrm{p}<0.001)$. The sum of the saturated fatty acids decreased linearly with increasing percentages of goat meat $(\mathrm{p}<0.01)$. Polyunsaturated fatty acids (PUFA), omega-3(n-3) and omega-6 (n-6) fatty acid and conjugated linoleic acid (CLA) concentrations demonstrated linear increase $(\mathrm{p}<0.05)$, with increasing percentages of goat meat in both the NRB and RB sausage formulations. The $\alpha$-tocopherol concentration of the NRB formulations did not change across the goat meat percentages, but with the RB formulations there was a linear increase with increasing percentages of goat meat $(\mathrm{p}<0.001)$. The cholesterol concentration decreased linearly with increasing percentages of goat meat in both the NRB and RB formulations ( $\mathrm{p}<0.01,<0.05$ respectively). The tasters preferred the NRB with higher goat meat percentage to the RB formulations. 
Conclusions: The NRB and RB sausage formulations with higher percentages of goat meat had higher concentrations of $\alpha$-tocopherol, CLA (18:2 cis 9 Trans 11), total n-3, total PUFA, total n3/total n-6 ratio, and a lower cholesterol concentration. The RB sausage formulations with higher percentages of goat meat had lower amount of saturation, in addition to an acceptable ratio of stearic acid (C18:0) + Oleic acid (C18:1) to palmitic acid (C16:0). The NRB formulations with greater percentage of goat meat were more acceptable by the tasters than the RB formulations.

Key words: Goat meat; rice bran; fatty acids; $\alpha$-tocopherol; cholesterol

\section{BACKGROUND}

Dietary habits are major factors in the development of obesity and cardiovascular heart diseases. Scientific documentation of the relationship between diet and obesity related diseases such as diabetes, heart disease, stroke, and some forms of cancer have been conducted and agreed upon by the scientific community [1]. For example, the obesity rate in Louisiana is $34.9 \%$, which is the fourth highest rate of obesity in the USA. Furthermore, Louisiana is in the top seven states in obesity-related medical expenditure [2]. Foods developed from animal products have been a part of human diets for years. Blood cholesterol level depends less on the intake of cholesterol from foods and more upon the amount of saturated fats consumed, especially the ratio of polyunsaturated to saturated fats [3]. A study demonstrated the effects of proper dietary intervention, with the mean blood cholesterol level of $90 \%$ of a test population being reduced by $3 \%$ to $23 \%$ [4].

One of the factors related to obesity and other diseases is the high consumption of red meats, such as pork and beef. The Census Bureau shows that in United States beef consumption is the highest in the world [5]. According to USDA [6], 90\% lean beef meat contains 10\% fat, 20\% protein, $69 \%$ water, $0.55 \%$ ash and $0 \%$ carbohydrates. The major saturated fatty acids in beef (myristic acid C14:0, palmitic acid C16:0 and stearic acid C18:0) have each been found to be significantly associated with coronary heart disease risk in the Nurses' Health Study [7], although some argue that a distinction should be made for stearic acid (C18:0), which has been discovered to have little cholesterol-raising effects in humans [8,9].

Lean goat meat is low in fat and saturated fatty acids, but high in unsaturated fatty acids, such as linoleic and oleic that has been shown to possess hypocholesteremic properties [10,11]. The chemical composition of goat meat is as follows: 74-76\% moisture, 20-22\% protein, 0.6$2.6 \%$ fat, and $1 \%$ ash [12]. Goat meat cuts have protein levels comparable to beef, lamb, and veal that were similarly prepared, but with lower fat content [13]. Additionally, the percentage of saturated fat in goat meat is lower than that of chicken, beef, pork, or lamb [14, 15]. Considering its high nutritional value and its greater unsaturated to saturated fatty acid ratio, goat meat has the potential to improve the health of susceptible populations without taking meat products out of their daily diet. Moreover, consumption of goat meat is becoming popular and is often available at the fine dining level [16].

Currently, there is an increased interest in the use of dietary antioxidants, including vitamins $\mathrm{C}$ and $\mathrm{E}$, to prevent cardiovascular diseases [17]. Rice bran oil antioxidants are very efficient in reducing low density lipoprotein (LDL) and total serum cholesterol [18]. Rice bran, a byproduct 
of the rice milling process, is a naturally rich source of antioxidants along with vitamins and minerals. Additionally, it contains $14-16 \%$ protein without gluten, $12-23 \%$ fat, and $8-10 \%$ crude fiber [19]. Nutritional studies in animals and humans have demonstrated the cholesterol lowering potential of rice bran and rice bran fractions [20, 21]. Rice bran fractions such as rice bran oil and soluble fiber are crucial factors in the regulation of plasma cholesterol levels, and the insoluble fiber plays an important role in intestinal regulation [22]. Substituting saturated fatty acids from meat in the diet with unsaturated fatty acids such as oleic, linoleic, and linolenic acids from rice bran lowered low-density lipoprotein-cholesterol in human subjects [23]. The protein in rice bran does not contain gluten; therefore, it is a healthy food choice for people with celiac disease. Approximately 1 in 133 people in the United States has celiac disease, an immunemediated disorder associated with gluten, a protein present in wheat, barley, and rye. Most affected individuals experience a remission of the disease after excluding gluten from their diets [24]. In June 2008, the United States Department of Agriculture Food Safety and Inspection Service (USDA/FSIS) approved the use of stabilized rice bran as a binder to a maximum of 3.5\% in various meat products such as sausage, meatballs, meat loaf, and meat patties [25]. Stabilized rice bran can hold moisture up to three times its weight, which can contribute to the juiciness of goat meat products. Rice bran also has a meat-like texture when it is cooked [26]. As a result, incorporating $3 \%$ of stabilized rice bran as a binder in goat meat sausages provides health benefits to the products [27].

In this study, sausages were formulated from a combination of goat meat and $90 \%$ lean ground beef to contain goat/beef percentages of either $50 / 50,75 / 25$ or $100 / 0$, with or without $3 \%$ stabilized rice bran. Cooked sausages from these formulations were analyzed for proximate, fatty acids, $\alpha$-tocopherol, cholesterol, and consumer acceptability.

\section{METHODS}

Preparation of Sausages: Goats were reared at the Southern University Agricultural Research and Extension Center (SUAREC) goat farm until they were humanely harvested and products were prepared. All meats were prepared in the state inspected Southern University Meat Processing Laboratory. Shoulder, leg, and other parts of one-to-three-year-old goats were deboned and ground together. Rice bran was obtained from Planters Rice Mill in Abbeville, LA and stabilized using microwave heat [28]. The stabilized rice bran was sieved with a 20 mesh screen, in order to remove broken rice and husks and to obtain a uniform particle size. Chili seasoning was obtained from Symrise Inc. (Symrise Inc., Teterboro, NJ). The ground sirloin was purchased from nearby grocery store ( $90 \%$ lean). The $90 \%$ lean cut was chosen because the percentage of fat was supposed to be close to the percentage of fat in goat meat.

Chili seasoning ( $3 \%$ by weight), salt ( $1.6 \%$ by weight), and water ( $3.3 \%$ by weight) were incorporated into the ground goat meat. Chili seasoning was used because the consumer preferred the taste in a workshop/ taste test conducted at SUAREC (data not shown). Chili seasoning and salt were added for taste, and water was added to provide moisture in the mix. The goat meat mixture was homogenized well and divided into two parts. Part one had no stabilized rice bran (NRB) and part two had stabilized rice bran (3\% by weight) (RB). Then each part of the meat mixtures samples were divided into three groups. Group one consisted of $100 \%$ goat 
meat, group two consisted of $75 \%$ (by weight) goat meat and $25 \%$ lean ground beef, and group three consisted of $50 \%$ (by weight) goat meat and 50\% lean ground beef. The goat/beef meat with no rice bran and goat/beef meat with rice bran mixtures were packed into collagen casing. The raw sausages were cooked in a preheated $\left(53.3^{\circ} \mathrm{C}\right)$ "Koch" stainless steel cooker/smoker (Koch Supply, North Kansas city, MO). The temperature was increased manually at $2.7^{\circ} \mathrm{C}$ per hour until the temperature of the cooker reached $65.5^{\circ} \mathrm{C}$. The smoker was then turned on and the temperature increased until the internal temperature of the sausages reached $70^{\circ} \mathrm{C}$ for at least 15 seconds. The cooking and smoking time took about 6 to 7 hours. Approximately, $500 \mathrm{~g}$ cooked sausage were homogenized in a Robot Coup R2 food processor (Robot Coup USA Inc., Ridgeland, MS) for two minutes to obtain a homogeneous sample. Three aliquots were prepared for sausages and were frozen at $-20^{\circ} \mathrm{C}$ until further analysis. Sausages were also placed in zip lock bags and stored in a freezer at $-20^{\circ} \mathrm{C}$ until the day of consumer acceptability test.

Proximate Analysis: On the day of analysis, samples were taken out of the freezer early in the morning and were thawed at room temperature (approximately $21^{\circ} \mathrm{C}$ ). Samples were analyzed using standard American Official of Analytical Chemists (AOAC approved methods (983.23, 992.15, 920.15, and 985.14) with modifications [29]. Lipids were extracted using a chloroform/methanol solution with butylated hydroxytoluene (BHT) as an antioxidant, and determined gravimetrically. Aliquots were taken from lipid extracts for determination of fatty acids. Protein content was determined using thermal conductivity on a Series II Nitrogen Analyzer 2410 (PerkinElmer Instruments, Norwalk, CT). Ash content was determined with using a Phoenix microwave furnace (CEM corp., Matthews, NC). Moisture content was determined using a Smart System 5 (CEM corp., Matthews, CT). Percentage of carbohydrate was determined by difference using formula: $\%$ Carbohydrate $=100-(\%$ Moisture $+\%$ Fat $+\%$ Ash + $\%$ Proteins). Each sample was run in triplicate.

Fatty Acid Determination: Lipid extracts aliquots (prepared during total lipid extraction) were used for the determination of fatty acid composition using a Varian Saturn 2100 (Agilent Technologies Inc., Wilmington DE) Gas Chromatography/Mass Spectrophotometer (GC/MS) with a fused silica column $(30 \times 0.25 \mathrm{~mm})$ [30]. GLC-490 Reference Standard and C23:0 methyl esters (Internal Standard) were purchased from Nu-Check Prep. Inc. (Elysian, Minnesota, USA) and used for determination of fatty acids. Each sample was run in triplicate.

Simultaneous Determination of $\alpha$-Tocopherol and Cholesterol: Cholesterol and $\alpha$-tocopherol were measured simultaneously on an 1100 Agilent High Performance Liquid Chromatography (HPLC) system (Agilent Technologies Inc. Wilmington DE). Homogenized sausage samples were prepared, extracted, and then quantified [31]. A ZORBAX RX-SIL $5 \mu \mathrm{m}, 4.8 \times 250 \mathrm{~mm}$ column was used. The mobile phase was composed of $99 \%$ hexane and $1 \%$ isopropyl alcohol (HPLC grade) at a flow rate of $0.5 \mathrm{~mL} / \mathrm{min}$. The total running time was 12 minutes. The detector was a diode array detector (DAD) operating at $\lambda=202 \mathrm{~nm}$. The injection volume was $5 \mu \mathrm{L}$ with a needle cleansing system and thermostat temperature of $20^{\circ} \mathrm{C}$. The $\alpha$-tocopherol and cholesterol standards and other chemicals were purchased from Sigma Aldrich Co. (St. Louis, MO). 
Standards were dissolved in hexane. Solutions with $500 \mathrm{ppm}$ of each standard were diluted volumetrically. A calibration curve for each component was made. The $\alpha$-tocopherol and cholesterol were detected using DAD and peak identification, which was accomplished by comparing the retention times and HPLC peaks with those obtained from standard solution of mixture analyzed under the same conditions. Quantitative determination was performed using the standard curve. Each sample was run in triplicate.

Consumer acceptability test: A five-point hedonic scale for food preference developed by Peryam and Pilgrim [32] was used to evaluate the six formulations of cooked sausage for aroma, tenderness, flavor and overall acceptability. Thirty three panelists, a combination of faculty, staff, and students of Southern University, were asked to rank one sample from each formulation. Before the taste, the participants were asked to sign a consent form and they were instructed the procedures. Smoked sausages were taken from the freezer one day before the taste session and thawed in the refrigerator overnight. Sausages were cut to 1 inch cubes and placed in a marked plate, heated in the microwave and served to the panelist. Each plate had all the samples. Panelists were asked to taste the sausages in a random order and rank aroma, tenderness, flavor and overall acceptability on the five-point hedonic scale with $1=$ extremely pleasant to $5=$ extremely unpleasant. Panelists used apple juice to cleanse their palates between sampling the next formulation. All evaluations were performed in a controlled environment in a sensory evaluation room with panelists seated in individually partitioned booths. The consumer acceptability test was approved by the Southern University Institutional Review Board (IRB).

Experimental Design and Statistical Analysis: The study was conducted as a two-factor experiment in a completely randomized design with three replicates. The two factors were rice bran presence (no rice bran and 3\% rice bran added) and three levels of beef meat inclusion as goat/beef percentages of 50/50,75/25, and 100/0. The experimental data was analyzed using the General Linear Models Procedure of SAS, version 9.3 [33]. The data was fitted to a fixed model, with the factors rice bran presence and beef meat level being treated as fixed effects. The treatment means were compared using the least squares means method of the General Linear Models Procedure of SAS, version 9.3. The effects of beef meat percentage were compared with trend analysis using orthogonal polynomial contrasts. The hedonic scale data from the sensory evaluation was fitted to an ordinal model for multinomial data using the Generalized Linear Models Procedure of SAS, version 9.3 [33]. Each characteristic (aroma, tenderness, flavor and overall acceptability) was analyzed separately. The significance level was set, prior to the experiment, at 0.05 for all analyses.

\section{Results and Discussion}

Proximate Analyses: The proximate analyses of the different combinations of goat meat and lean beef sausages, with either NRB or RB are presented in Table 1. Moisture and carbohydrate concentrations increased linearly in response to increasing percentages of goat meat for both the $\mathrm{NRB}$ and RB formulations. The fat concentration decreased linearly in response to the increasing percentages of goat meat for both the NRB and RB formulations. This decrease in fat may reflect 
the lower fat concentration of goat meat compared to beef (the fat content of raw goat and beef meat used in this study was $12 \%$ and $19 \%$ respectively). The NRB mean (across the goat meat percentages) for fat concentration was less than the RB mean (across the goat meat percentages). This could be due to addition of rice bran into the different combination of meat samples. Proximate analysis of rice bran used in this study showed $15.6 \%$ fat, $11.5 \%$ protein, $18.4 \%$ moisture, $9.6 \%$ ash and $45.1 \%$ carbohydrates. The results from previous study by Malekian et al [34] showed $17.5 \%$ fat, $17.5 \%$ protein, $8.4 \%$ moisture, $7.6 \%$ ash, and $48.9 \%$ carbohydrates. This difference in the results could be due to different varieties of rice, soil, and storing conditions $[34,19]$. Neither ash nor protein concentration exhibited a significant change in response to the increasing goat meat percentages.

Table 1. Proximate analysis of sausages formulated with varying goat/beef meat percentages, with and without $3 \%$ rice bran added.

\begin{tabular}{|c|c|c|c|c|c|c|c|c|c|c|}
\hline \multirow{3}{*}{$\begin{array}{l}\text { Proximate } \\
\text { analysis }\end{array}$} & \multicolumn{5}{|c|}{ No rice bran added (NRB) } & \multicolumn{5}{|c|}{ Rice bran added (RB) } \\
\hline & \multicolumn{2}{|c|}{$\begin{array}{l}\text { Goat/beef } \\
\text { percentage }^{\S}\end{array}$} & \multirow{2}{*}{$\frac{\text { meat }}{100 / 0}$} & \multirow[b]{2}{*}{$\operatorname{Mean}^{\dagger}$} & \multirow[b]{2}{*}{$\mathrm{L}^{\partial}$} & \multicolumn{2}{|c|}{$\begin{array}{l}\text { Goat/beef } \\
\text { percentage }^{\S}\end{array}$} & meat & \multirow[b]{2}{*}{ Mean $^{\dagger}$} & \multirow[b]{2}{*}{$\mathrm{L}^{\partial}$} \\
\hline & $50 / 50$ & $75 / 25$ & & & & $50 / 50$ & $75 / 25$ & $100 / 0$ & & \\
\hline & \multicolumn{3}{|c|}{ ( \% by weight \pm SME) } & & & \multicolumn{3}{|c|}{ ( \% by weight \pm SME) } & & \\
\hline Moisture & $\begin{array}{l}51.19 \\
\pm 0.08\end{array}$ & $\begin{array}{l}52.33 \\
\pm 0.44\end{array}$ & $\begin{array}{l}53.32 \\
\pm 0.16\end{array}$ & $\begin{array}{l}52.28^{\mathrm{A}} \\
\pm 0.32\end{array}$ & $* * *$ & $\begin{array}{l}51.18 \\
\pm 0.13\end{array}$ & $\begin{array}{l}51.61 \\
\pm 0.22\end{array}$ & $\begin{array}{l}53.24 \\
\pm 0.11\end{array}$ & $\begin{array}{l}52.01^{\mathrm{A}} \\
\pm 0.32\end{array}$ & $* * *$ \\
\hline Fat & $\begin{array}{l}19.75 \\
\pm 0.24\end{array}$ & $\begin{array}{l}18.15 \\
\pm 0.58\end{array}$ & $\begin{array}{l}15.47 \\
\pm 0.27\end{array}$ & $\begin{array}{l}17.79^{\mathrm{B}} \\
\pm 0.47\end{array}$ & $* * *$ & $\begin{array}{l}20.35 \\
\pm 0.35\end{array}$ & $\begin{array}{l}19.48 \\
\pm 0.24\end{array}$ & $\begin{array}{l}15.74 \\
\pm 0.13\end{array}$ & $\begin{array}{l}18.52^{\mathrm{A}} \\
\pm 0.47\end{array}$ & $* * *$ \\
\hline Ash & $\begin{array}{l}4.31 \\
\pm 0.09\end{array}$ & $\begin{array}{l}4.30 \\
\pm 0.08\end{array}$ & $\begin{array}{l}4.45 \\
\pm 0.01\end{array}$ & $\begin{array}{l}4.35^{\mathrm{A}} \\
\pm 0.16\end{array}$ & ns & $\begin{array}{l}4.37 \\
\pm 0.10\end{array}$ & $\begin{array}{l}4.46 \\
\pm 0.24\end{array}$ & $\begin{array}{l}4.23 \\
\pm 0.07\end{array}$ & $\begin{array}{l}4.36^{\mathrm{A}} \\
\pm 0.16\end{array}$ & ns \\
\hline Protein & $\begin{array}{l}22.18 \\
\pm 0.20\end{array}$ & $\begin{array}{l}21.72 \\
\pm 0.32\end{array}$ & $\begin{array}{l}22.58 \\
\pm 0.14\end{array}$ & $\begin{array}{l}22.16^{\mathrm{A}} \\
\pm 0.46\end{array}$ & $\mathrm{~ns}$ & $\begin{array}{l}21.11 \\
\pm 0.65\end{array}$ & $\begin{array}{l}21.42 \\
\pm 0.18\end{array}$ & $\begin{array}{l}21.91 \\
\pm 0.09\end{array}$ & $\begin{array}{l}21.48^{\mathrm{B}} \\
\pm 0.46\end{array}$ & ns \\
\hline Carbohydrates & $\begin{array}{l}2.58 \\
\pm 0.24\end{array}$ & $\begin{array}{l}3.51 \\
\pm 0.07\end{array}$ & $\begin{array}{l}4.18 \\
\pm 0.08\end{array}$ & $\begin{array}{l}3.42^{\mathrm{A}} \\
\pm 0.32\end{array}$ & $* *$ & $\begin{array}{l}2.99 \\
\pm 0.41\end{array}$ & $\begin{array}{l}3.03 \\
\pm 0.42\end{array}$ & $\begin{array}{l}4.87 \\
\pm 0.18\end{array}$ & $\begin{array}{l}3.63^{\mathrm{A}} \\
\pm 0.20\end{array}$ & $* * *$ \\
\hline
\end{tabular}

${ }^{\S}$ Data are presented as mean of replicates, $(n=3)$.

${ }^{\dagger}$ Mean of the three goat/beef meat percentages. Goat/beef meat percentage means, within a row, followed by different upper case letters differ at $\mathrm{p} \leq 0.05$.

${ }^{*}$ The goat/beef meat percentage by rice bran interaction was not significant $(\mathrm{p} \leq 0.05)$ for any of the proximate analysis determinations.

${ }^{\partial}$ Linear effect.

**, $* * *$ Significant at the $0.05,0.01,0.001$ level of probability, respectively, from orthogonal contrasts, $\mathrm{ns}=$ not significant.

Fatty Acids: Fatty acids are important components of meat lipids [14], because they can have an important influence on human plasma cholesterol level. The fatty acid content, as a percentage of total fatty acids, for goat meat reported in the literature are oleic acid (C18:1) 28-50\%, palmitic (C16:0) 15-31\%, stearic (C18:0) 6-17\%, and linoleic (C18:2) 4-15\% [14]. Beef has oleic acid 
(C18:1) about 33\%, palmitic (C16:0) about 27\%, stearic (C18:0) about 18\% and linoleic (C18:2) about $3.5 \%$ [35.]

Saturated fatty acids, in contrast to total monounsaturated fatty acids (MUFA) and total polyunsaturated fatty acids (PUFA), increase cholesterol levels. Not all saturated fatty acids have the same influence on the cholesterol level; C16:0 and C14:0 can increase cholesterol levels, while C18:0 does not have this effect [14].

The fatty acid analyses of the six formulations of goat meat and lean beef with either NRB or RB, used in this study, are presented in Table 2. The NRB means (across the goat meat percentages) for the levels of the saturated fatty acids (C14:0 and C16:0) were greater than the $\mathrm{RB}$ means (across the goat meat percentages). The C18:0 concentrations increased linearly in response to the increasing percentages of goat meat in the NRB formulations, but did not change across the RB formulations. The NRB mean (across the goat meat percentages) for the C18:0 concentration was less than the RB mean (across the goat meat percentages).

A high concentration of $\mathrm{C} 18: 0$ in meat will not increase cholesterol levels in humans, and more importantly, the ratio of $(\mathrm{C} 18: 0+\mathrm{C} 18: 1)$ to $\mathrm{C} 16: 0$ could have beneficial health effects when it falls between 2 and 3 [14]. The NRB formulations exhibited a (C18:0 + C18:1) to C16:0 ratio marginally below the healthy range of 2 to 3 , but all goat meat sausage formulations with $\mathrm{RB}$ were within the healthy range.

The sum of saturated fatty acids ( $\sum$ Sat) did not vary across the goat meat percentages for the NRB sausage formulations, but in the RB formulations the $\sum$ Sat decreased linearly in response to the increasing percentages of goat meat.

Meat can be also classified to have health benefits by its concentration of desirable fatty acids (DFA) which include the total of C18:0 and all unsaturated fatty acids. These DFA are considered to have either neutral or cholesterol lowering effects [14]. The NRB mean (across the goat meat percentages) for the DFA concentration was lower than the RB mean (across the goat meat percentages). The DFA concentration did not vary across the goat meat percentages for either the NRB or RB formulations.

Monounsaturated fatty acids such as transvaccenic acid (TVA) (C18:1 trans-11) are important in the human bodies' production of conjugated linolenic acids (CLA). TVA can raise bad cholesterol in serum [36], but the conversion to CLA is a benefit for human health. Evidence is accumulating that different trans 18:1isomers have differential effects on plasma LDL cholesterol, with this being an area of active investigation [36]. For example, there is growing evidence and support that trans-9 and trans-10 18:1 are more powerful in increasing plasma LDL cholesterol than trans-11 18:1 [37]. It is also recognized that trans vaccenic acid (trans-11 18:1, TVA) is the precursor for tissue synthesis of beneficial CLA (CLA cis-9, trans-11) in both humans and in animals [38]. Interest in CLA has increased because of its health benefits [39]. For example, Dannenberger et al. [40] reported 10 isomers of CLA in beef with CLA cis-9, trans-11 representing approximately $70 \%$ of total CLA isomers. Biological effects have been widely investigated for two of these isomers. The anticarcinogenic and antiatherogenic effects of cis-9, trans-11 and the anti-obesity effects of trans-10, cis-12 have also been well documented [41]. In this study, the TVA (transvassenic acid C18:1 Trans11) concentration increased in response to the increasing percentages of goat meat for the NRB formulations. In the RB 
formulations, TVA also increased across the increasing percentages of goat meat, but the effect was not significant $(\mathrm{p}<0.095)$. The $\Sigma$ MUFA concentration decreased linearly in response to the increasing percentages of goat meat in the NRB sausage formulations, but did not change across the RB formulations. The NRB mean (across the goat percentages) for total MUFA was greater than the RB mean (across the goat meat percentages).

Linoleic acid (C18:2; omega-6) and alphalinolenic acid (C18:3; omega-3), are plant fatty acids that can be transformed to conjugated linoleic acid (CLA) by bacteria in the rumen [42]. Plants do not synthesize CLA. The major sources of CLA in the human diet are meat and dairy products derived from ruminants, and in these products the predominant CLA isomer (>90\%) is cis 9 trans11 [43]. In this study, the CLA (C18:2 cis 9 trans11) concentration increased linearly in response to the increasing percentages of goat meat for both the NRB and RB formulations. The CLA (18:2 Trans 11, cis 12) concentration did not change across the goat meat percentages for either the NRB or the RB formulations.

Essential omega-6 (n-6) and omega-3 (n-3) fatty acids play a crucial role in the human body. They carry the fat soluble vitamins (A, D, E and K) and support animal and human immune systems. These fatty acids cannot be synthesized by human organisms and need to be consumed in the diet [44]. It is expected that adding stabilized rice bran and chili seasoning components can increase total n-6 and n-3 in sausages and make them more healthy [27]. The stabilized rice bran and chili seasoning were analyzed for total $\mathrm{n}-6$ and total $\mathrm{n}-3$ fatty acids, with the results being: total n-6 $25.79 \%$ and total n-3 $1.7 \%$ for rice bran, in addition to total n- $637.97 \%$ and total n-3 $3.94 \%$ for chili seasoning. In this study, the essential fatty acids concentrations of C18:2 n-6, and C18:3 n-6 in the NRB formulations increased across the increasing percentage of goat meat, but the effect was not significant ( $p=0.157$ and 0.390 respectively). In the RB formulations the $n-6$ and $\mathrm{n}-3$ fatty acids increased linearly in response to the increasing percentages of goat meat. The C18:3 $n-3$ concentrations also increased linearly in response to the increasing percentages of goat meat for both the NRB and RB formulations.

The total PUFA concentration increased linearly in response to the increasing percentages of goat meat in both the NRB and RB formulations. The NRB mean (across the goat percentages) for total PUFA was less than the RB mean (across the goat percentages).

The sums of essential fatty acids total $n-6$, total $n-3$ concentrations and the ratio of total $n$ $3 /$ total n-6 increased linearly in response to the increasing percentages of goat meat in both the NRB and RB formulations. Additionally, the NRB mean for both total n- 6 and total n-3 and the total $n-3 /$ total $n-6$ ratio (across the goat meat percentages) was less than the RB mean (across the goat meat percentages).

Table 2. Fatty acid composition of sausages formulated with varying goat/beef meat percentages, with and without $3 \%$ rice bran added.

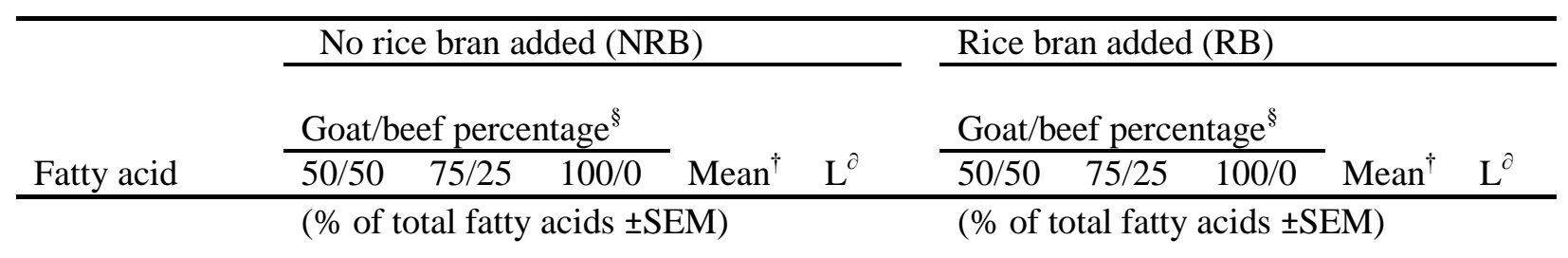


Saturated fatty acids

$\begin{array}{llllll}\mathrm{C} 14: 0 & 4.80 & 4.78 & 4.44 & 4.67^{\mathrm{A}} & \mathrm{ns} \\ & \pm 0.09 & \pm 0.14 & \pm 0.23 & \pm 0.99 & \\ \mathrm{C} 16: 0 & 28.56 & 28.31 & 28.14 & 28.34^{\mathrm{A}} & \mathrm{ns} \\ & \pm 0.14 & \pm 0.22 & \pm 0.18 & \pm 0.11 & \\ \mathrm{C} 17: 0 & 1.88^{\mathrm{a}} & 2.09^{\mathrm{a}} & 2.22^{\mathrm{a}} & 2.06^{\#} & * \\ & \pm 0.09 & \pm 0.01 & \pm 0.1 & \pm 0.006 & \\ \mathrm{C} 18: 0 & 20.76^{\mathrm{b}} & 21.22^{\mathrm{b}} & 21.74^{\mathrm{b}} & 21.24^{\#} & * * \\ & \pm 0.11 & \pm 0.02 & \pm 0.38 & \pm 0.18 & \end{array}$

Monounsaturated fatty acids

$\begin{array}{llllll}\text { C16:1 } & 4.29^{\mathrm{a}} & 3.79^{\mathrm{a}} & 2.86^{\mathrm{a}} & 3.65^{\#} & * * * \\ & \pm 0.28 & \pm 0.08 & \pm 0.05 & \pm 0.23 & \\ \text { C18:1 Trans 11 } & 0.12 & 0.67 & 1.11 & 0.63^{\mathrm{A}} & * \\ & \pm 0.03 & \pm 0.6 & \pm 0.27 & \pm 0.24 & \\ \mathrm{C} 18: 1 & 33.73 & 32.81 & 32.48 & 33.01^{\mathrm{A}} & * * * \\ & \pm 0.1 & \pm 0.17 & \pm 0.03 & \pm 0.20 & \end{array}$

Polyunsaturated fatty acids

\begin{tabular}{|c|c|c|c|c|c|c|c|c|c|c|}
\hline C18:2 n-6 & $\begin{array}{l}3.42 \\
\pm 0.25\end{array}$ & $\begin{array}{l}3.65 \\
\pm 0.02\end{array}$ & $\begin{array}{l}4.07 \\
\pm 0.64\end{array}$ & $\begin{array}{l}3.71^{\mathrm{A}} \\
\pm 0.22\end{array}$ & ns & $\begin{array}{l}3.11 \\
\pm 0.08\end{array}$ & $\begin{array}{l}3.53 \\
\pm 0.3\end{array}$ & $\begin{array}{l}4.26 \\
\pm 0.08\end{array}$ & $\begin{array}{l}3.63^{\mathrm{A}} \\
\pm 0.19\end{array}$ & * \\
\hline C18:3 n-6 & 0.02 & 0.02 & 0.03 & $0.02^{\mathrm{A}}$ & ns & 0.01 & 0.04 & 0.03 & $0.03^{\mathrm{A}}$ & $*$ \\
\hline & \pm 0.01 & \pm 0.01 & \pm 0.01 & \pm 0.004 & & \pm 0.01 & \pm 0.01 & \pm 0.01 & \pm 0.005 & \\
\hline C18:3 n-3 & 0.23 & 0.37 & 0.37 & $0.34^{\mathrm{B}}$ & $*$ & 0.33 & 0.50 & 0.61 & $0.48^{\mathrm{A}}$ & $*$ \\
\hline & \pm 0.08 & $\pm 0 . .01$ & $\pm 0.01^{\mathrm{a}}$ & \pm 0.03 & & \pm 0.03 & \pm 0.01 & \pm 0.02 & \pm 0.04 & \\
\hline C18:2 cis9 & 0.66 & 0.72 & 0.82 & $0.73^{\mathrm{A}}$ & $* *$ & 0.63 & 0.79 & 0.88 & $0.77^{\mathrm{A}}$ & $* * *$ \\
\hline $\operatorname{trans} 11 \mathrm{CLA}$ & \pm 0.05 & \pm 0.03 & \pm 0.06 & \pm 0.03 & & \pm 0.01 & \pm 0.01 & \pm 0.01 & \pm 0.04 & \\
\hline $\mathrm{C} 18: 2$ trans 11 & 0.003 & 0.007 & 0.013 & $0.01^{\mathrm{A}}$ & ns & 0.013 & 0.0 & 0.010 & $0.01^{\mathrm{A}}$ & ns \\
\hline cis 12 CLA & \pm 0.01 & \pm 0.01 & \pm 0.01 & \pm 0.002 & & \pm 0.01 & \pm 0.00 & \pm 0.01 & \pm 0.003 & \\
\hline$C 20: 2 n-6$ & 0.0 & 0.007 & 0.007 & $0.004^{\mathrm{B}}$ & ns & 0.020 & 0.02 & 0.027 & $0.022^{\mathrm{A}}$ & ns \\
\hline & \pm 0.00 & \pm 0.01 & \pm 0.01 & \pm 0.002 & & \pm 0.01 & \pm 0.01 & \pm 0.01 & \pm 0.004 & \\
\hline $\mathrm{C} 20: 3 \mathrm{n}-3$ & $0.09^{\mathrm{a}}$ & $0.07^{\mathrm{a}}$ & $0.09^{\mathrm{a}}$ & $0.08^{\#}$ & ns & $0.02^{\mathrm{b}}$ & $0.10^{\mathrm{a}}$ & $0.11^{\mathrm{a}}$ & $0.08^{\#}$ & $* *$ \\
\hline & \pm 0.02 & \pm 0.02 & \pm 0.01 & \pm 0.01 & & \pm 0.01 & \pm 0.01 & \pm 0.03 & \pm 0.02 & \\
\hline C20:3 n-6 & 1.09 & 1.21 & 1.19 & $1.16^{\mathrm{A}}$ & ns & 1.47 & 1.59 & 1.63 & $1.56^{\mathrm{A}}$ & ns \\
\hline & \pm 0.06 & \pm 0.09 & \pm 0.6 & \pm 0.18 & & \pm 0.03 & \pm 0.2 & \pm 0.16 & \pm 0.08 & \\
\hline C20:5 n-3 & $0.03^{\mathrm{a}}$ & $0.00^{\mathrm{b}}$ & $0.15^{\mathrm{a}}$ & $0.06^{\#}$ & $* *$ & $0.04^{\mathrm{a}}$ & $0.12^{\mathrm{a}}$ & $0.13^{\mathrm{a}}$ & $0.10^{\#}$ & $*$ \\
\hline & \pm 0.02 & \pm 0.00 & \pm 0.05 & \pm 0.03 & & \pm 0.02 & \pm 0.02 & \pm 0.01 & \pm 0.02 & \\
\hline Sums and $r$ & t & & & & & & & & & \\
\hline$\Sigma$ Sat & $56.1^{\mathrm{b}}$ & $56.5^{\mathrm{b}}$ & $56.65^{\mathrm{b}}$ & $55.42^{\#}$ & ns & $61.59^{\mathrm{a}}$ & $61.03^{\mathrm{a}}$ & $60.22^{\mathrm{a}}$ & $60.95^{\#}$ & $* *$ \\
\hline & \pm 0.22 & $\pm 0.35^{\mathrm{a}}$ & \pm 0.4 & \pm 0.19 & & \pm 0.18 & \pm 0.46 & \pm 0.1 & \pm 0.25 & \\
\hline$\Sigma$ MUFA & 38.23 & 37.33 & 36.45 & $37.34^{\mathrm{A}}$ & $* *$ & 32.67 & 32.18 & 31.98 & $32.27^{\mathrm{B}}$ & ns \\
\hline & \pm 0.42 & \pm 0.47 & $\pm 0.32^{\mathrm{a}}$ & \pm 0.33 & & \pm 0.21 & \pm 0.36 & \pm 0.24 & \pm 0.17 & \\
\hline$\Sigma$ PUFA & 5.67 & 6.17 & 6.9 & $6.25^{\mathrm{B}}$ & $* *$ & 5.75 & 6.79 & 7.8 & $6.78^{\mathrm{A}}$ & $* * *$ \\
\hline & \pm 0.42 & \pm 0.15 & \pm 0.1 & \pm 0.22 & & \pm 0.07 & \pm 0.14 & \pm 0.32 & \pm 0.31 & \\
\hline DFA & 64.66 & 64.71 & 65.09 & $64.82^{\mathrm{B}}$ & ns & 71.04 & 71.51 & 71.95 & $71.50^{\mathrm{A}}$ & $\mathrm{ns}$ \\
\hline & \pm 0.21 & \pm 0.35 & \pm 0.21 & \pm 0.15 & & \pm 0.31 & \pm 0.5 & \pm 0.12 & \pm 0.22 & \\
\hline$(\mathrm{C} 18: 0+\mathrm{C} 18: 1) /$ & 1.91 & 1.91 & 1.93 & $1.92^{\mathrm{B}}$ & ns & 2.66 & 2.66 & 2.64 & $2.65^{\mathrm{A}}$ & ns \\
\hline C16:0 & \pm 0.01 & \pm 0.01 & \pm 0.02 & \pm 0.01 & & \pm 0.08 & \pm 0.02 & \pm 0.02 & \pm 0.02 & \\
\hline$\Sigma$ PUFA $/ \Sigma$ Sat & 0.10 & 0.11 & 0.12 & $0.11^{\mathrm{A}}$ & $* *$ & 0.09 & 0.11 & 0.13 & $0.11^{\mathrm{A}}$ & *** \\
\hline & \pm 0.01 & \pm 0.00 & \pm 0.01 & \pm 0.004 & & \pm 0.01 & \pm 0.00 & \pm 0.01 & \pm 0.006 & \\
\hline
\end{tabular}

$\begin{array}{lllll}3.62 & 3.57 & 3.51 & 3.56^{\mathrm{B}} & \mathrm{ns} \\ \pm 0.2 & \pm 0.55 & \pm 0.03 & \pm 017 & \\ 23.66 & 23.44 & 23.14 & 23.42^{\mathrm{B}} & \mathrm{ns} \\ \pm 0.51 & \pm 0.09 & \pm 0.05 & \pm 0.17 & \\ 1.62^{\mathrm{b}} & 1.43^{\mathrm{b}} & 1.34^{\mathrm{b}} & 1.46^{\#} & * \\ \pm 0.12 & \pm 0.07 & \pm 0.07 & \pm 0.06 & \\ 32.63^{\mathrm{a}} & 32.54^{\mathrm{a}} & 32.17^{\mathrm{a}} & 32.45^{\#} & \mathrm{~ns} \\ \pm 0.31 & \pm 0.06 & \pm 0.1 & \pm 0.12 & \end{array}$

$\begin{array}{lllll}2.35^{\mathrm{b}} & 2.19^{\mathrm{b}} & 2.13^{\mathrm{b}} & 2.22^{\#} & \mathrm{~ns} \\ \pm 0.02 & \pm 0.02 & \pm 0.01 & \pm 0.03 & \\ 0.08 & 0.1 & 0.78 & 0.32^{\mathrm{A}} & \mathrm{ns} \\ \pm 0.01 & \pm 0.01 & \pm 0.14 & \pm 0.12 & \\ 30.23 & 29.76 & 28.92 & 29.63^{\mathrm{B}} & * * * \\ \pm 0.2 & \pm 0.31 & \pm 0.25 & \pm 0.23 & \end{array}$

Rice bran added (RB) 


\begin{tabular}{|c|c|c|c|c|c|c|c|c|c|c|}
\hline \multirow{3}{*}{$\Sigma \mathrm{n}-6$} & \multicolumn{5}{|c|}{ No rice bran added (NRB) } & \multicolumn{5}{|c|}{ Rice bran added (RB) } \\
\hline & 4.55 & 4.91 & 5.33 & $4.93^{\mathrm{B}}$ & $* *$ & 4.62 & 5.19 & 5.94 & $5.25^{\mathrm{A}}$ & $* * *$ \\
\hline & \pm 0.3 & \pm 0.1 & \pm 0.06 & \pm 0.15 & & \pm 0.06 & \pm 0.14 & \pm 0.24 & \pm 0.21 & \\
\hline \multirow[t]{2}{*}{$\Sigma \mathrm{n}-3$} & 0.46 & 0.54 & 0.75 & $0.58^{\mathrm{B}}$ & $*$ & 0.49 & 0.81 & 0.96 & $0.75^{\mathrm{A}}$ & $* * *$ \\
\hline & \pm 0.1 & \pm 0.03 & \pm 0.09 & \pm 0.06 & & \pm 0.06 & \pm 0.02 & \pm 0.09 & \pm 0.08 & \\
\hline \multirow[t]{2}{*}{$\Sigma n-3 / \Sigma n-6$} & 0.1 & 0.11 & 0.14 & $0.12^{\mathrm{B}}$ & $*$ & 0.11 & 0.16 & 0.16 & $0.14^{\mathrm{A}}$ & $* *$ \\
\hline & \pm 0.02 & \pm 0.01 & \pm 0.02 & \pm 0.01 & & \pm 0.02 & \pm 0.01 & \pm 0.01 & \pm 0.01 & \\
\hline
\end{tabular}

${ }^{\S}$ Data are presented as mean of replicates. $(n=3)$.

${ }^{\dagger}$ Mean of the three goat/beef percentages, $(n=9)$. Goat/beef percentage means, within a row, followed by different upper case letters differ at $\mathrm{P} \leq 0.05$.

${ }^{\#}$ The goat/beef percentage by rice bran interaction was significant $(\mathrm{p} \leq 0.05)$. So, the no rice bran added and rice bran added means were not compared. Within a goat/beef percentage and within a row, means followed by different lower case letters differ $(\mathrm{p} \leq 0.05)$.

${ }^{\partial}$ Linear effect.

$*, * *, * * *$ Significant at the $0.05,0.01,0.001$ level of probability, respectively, from orthogonal contrasts, ns $=$ not significant.

$\sum$ Sat $=$ sum of saturated fatty acids; $\sum$ MUFA $=$ sum of monounsaturated fatty acids; $\sum$ PUFA = sum of polyunsaturated fatty acids. DFA (Desired fatty acids) $=\mathrm{C} 18: 0+\sum$ MUFA $+\sum$ PUFA; $\sum$ n6 = sum of omega-6 fatty acids; $\sum \mathrm{n} 3=$ sum of omega-3 fatty acids

$\alpha$-Tocopherol and Cholesterol Concentrations: The $\alpha$-tocopherol and cholesterol concentrations of the six formulations of goat meat and lean beef meat sausages, with either $\mathrm{NRB}$ or RB are presented in Table 3. The $\alpha$-tocopherol concentration did not vary across the goat meat percentages for the NRB formulations. However, in the RB formulation, it increased in response to the increasing percentages of goat meat. The $\alpha$-tocopherol concentration was less at each of the goat meat percentages in both the NRB formulations than the RB formulations. Nonetheless, higher $\alpha$-tocopherol concentrations are expected in the RB formulations, due to the $\alpha$-tocopherol content of rice bran [45]. Moreover, while high temperatures can cause $\alpha$ tocopherol degradation, a previous study has shown no significant degradation with the cooking conditions used in this experiment [46]. The cholesterol concentration decreased linearly in response to the increasing percentages of goat meat in both the NRB and RB formulations. The $\mathrm{NRB}$ mean (across the goat meat percentages) for cholesterol was greater than the RB mean (across the goat meat percentages).

Table 3. Cholesterol and $\alpha$-tocopherol concentration of sausages formulated with varying goat/beef meat percentages, with and without $3 \%$ rice bran added.

\begin{tabular}{|c|c|c|c|c|c|c|c|c|c|c|}
\hline & \multicolumn{5}{|c|}{ No rice bran added (NRB) } & \multicolumn{5}{|c|}{ Rice bran added (RB) } \\
\hline & \multicolumn{3}{|c|}{ Goat/beef percentage } & \multirow[b]{2}{*}{ Mean $^{\dagger}$} & \multirow[b]{2}{*}{$\mathrm{L}^{\partial}$} & \multicolumn{3}{|c|}{ Goat/beef percentage } & \multirow[b]{2}{*}{ Mean $^{\dagger}$} & \multirow[b]{2}{*}{$\mathrm{L}^{\partial}$} \\
\hline & $50 / 50$ & $75 / 25$ & $100 / 0$ & & & $50 / 50$ & $75 / 25$ & $100 / 0$ & & \\
\hline & \multicolumn{3}{|c|}{$(\mathrm{mg} / 100 \mathrm{~g} \pm \mathrm{SEM})$} & & & \multicolumn{3}{|c|}{$(\mathrm{mg} / 100 \mathrm{~g} \pm \mathrm{SEM})$} & & \\
\hline \multirow[t]{2}{*}{ Cholesterol } & 67.69 & 63.12 & 58.84 & $63.22^{\mathrm{A}}$ & \multirow[t]{2}{*}{$* *$} & 62.39 & 60.80 & 58.07 & $60.42^{\mathrm{B}}$ & \multirow[t]{2}{*}{$*$} \\
\hline & \pm 1.21 & \pm 0.34 & \pm 0.89 & \pm 1.83 & & \pm 0.68 & \pm 2.07 & \pm 1.75 & \pm 1.83 & \\
\hline \multirow[t]{2}{*}{$\alpha$-tocopherol } & $1.74^{\mathrm{b}}$ & $1.76^{\mathrm{b}}$ & $1.80^{\mathrm{b}}$ & $1.77^{\#}$ & \multirow[t]{2}{*}{$\mathrm{ns}$} & $2.26^{\mathrm{a}}$ & $2.63^{\mathrm{a}}$ & $2.81^{\mathrm{a}}$ & $2.57^{\#}$ & \multirow[t]{2}{*}{$* * *$} \\
\hline & \pm 0.03 & \pm 0.02 & \pm 0.06 & \pm 0.07 & & \pm 0.08 & \pm 0.06 & \pm 0.07 & \pm 0.07 & \\
\hline
\end{tabular}


${ }^{\S}$ Data are presented as mean of replicates. $(n=3)$.

${ }^{\dagger}$ Mean of the three goat/beef percentages, $(n=9)$. Goat/beef percentage means, within a row, followed by different upper case letters differ at $\mathrm{p} \leq 0.05$.

${ }^{\#}$ The goat/beef meat percentage by rice bran interaction was significant $(\mathrm{p} \leq 0.05)$. So, the no rice bran added and rice bran added means were not compared. Within a goat/beef meat percentage and within a row, means followed by different lower case letters differ $(\mathrm{p} \leq 0.05)$.

${ }^{\partial}$ Linear effect.

$*, * *, * * *$ Significant at the $0.05,0.01,0.001$ level of probability, respectively, from orthogonal contrasts, $\mathrm{ns}=$ not significant.

\section{Consumer acceptability test:}

Contrasts are tested using odds ratios in higher taste categories. The taste categories from highest to lowest are: 1) extremely pleasant, 2) moderately pleasant, 3) neither like-nor-dislike, 4) moderately unpleasant, 5) extremely unpleasant. The entity on the left-hand side of each contrast, shown in brackets, is the numerator for the odds ratio and the entity on the right-hand side is the denominator (Table 4). So, an odds ratio of 5 indicates that the left-hand entry is 5 times more likely to be in the higher taste categories than the right-hand entry.

\section{Contrasts between no rice bran added (NRB) and rice bran added (RB) formulations:}

Odds ratios showed that the odds of the NRB added formulations being in the higher taste categories, compared to that of the RB added formulations, were significant for 5 of the 12 contrast-characteristic combinations (Table 4). The odds of the RB added formulations being in the higher taste categories than the NRB added formulations were not significant for any of the 12 contrast-characteristic combinations.

\section{Contrasts among goat/beef percentages with the no rice bran added (NRB) formulations:}

The odds ratios, across the 9 contrast-characteristic combinations, showed a pattern of taster preference for the greater percentage of goat meat formulations. The 100/0 goat/beef formulation was 2.7 times more likely to be in the higher taste categories than the $75 / 25$ goat/beef formulation for the aroma characteristic. Furthermore, the 100/0 goat/beef formulation was 2.5 times more likely to be in the higher taste categories than the 75/25 goat/beef formulation for the characteristic flavor. However, the p-value for this odds ratio was 0.0502 . None of the contrastcharacteristic combinations showed a significant taster preference for a lower percentage goat meat formulation.

\section{Contrasts among goat/beef percentages with the rice bran added (RB) formulations:}

The odds ratio, across the 9 contrast-characteristic combinations, showed a pattern of taster preference for the greater percentage goat meat formulations. Odds ratios show (Table 4) that the odds of the greater percentage goat meat formulations being in the higher taste categories than the less percentage goat meat formulations was significant for 3 of the 9 contrast-characteristic combinations. Additionally, the 100/0 goat/beef formulation was 2.5 times more likely to be in the higher taste categories than the 50/50 goat/beef formulation for the characteristic of flavor, but $\mathrm{p}$-value for this odds ratio was 0.0505 . Across the nine contrasts the lower percentage of goat meat was not preferred. None of the 9 contrast-characteristic formulations showed a significant 
preference for lower percentage goat meat formulations. Therefore, it can be concluded that the tasters preferred sausage with greater percentage goat meat without rice bran compared to the other formulations.

In the previous studies [47-48], researchers have concluded that the use of goat meat, either alone or in combination with beef, can be one way to produce lower fat in meat products, and with acceptable sensory characteristics that can appeal to people who do not typically consume goat meat. In a study conducted by Cosenza et al [49], 65\% of the panelists expressed that they would purchase goat meat sausages with or without added soy. Moreover, goat meat can improve emulsification, texture and flavor in goat meat products [47]. Addition of oatrim or oat gum to goat meat patties produced products were acceptable to consumers, with scores of 6 or above [50]. In a study conducted by Bratcher, et al [51], it was concluded that the frankfurters processed with 3 different sources of fat were moderately or slightly liked by the tasters. In our study, the panelists liked $100 \%$ goat meat without added rice bran more than any other formulations. Additionally, in the present study the tasters preferred higher percentage of goat meat sausage formulations when compared to the results from previous study, in which they incorporated less percentage of goat meat into their products [49-51].

Table 4. Sensory evaluation of sausages formulated with varying goat/beef meat percentages, with and without $3 \%$ rice bran added.

\begin{tabular}{|c|c|c|c|c|}
\hline & Characteristic & & & \\
\hline & Aroma & Tenderness & Flavor & $\begin{array}{l}\text { Overall } \\
\text { acceptability }\end{array}$ \\
\hline Contrast $^{\#}$ & $\begin{array}{ll}\text { Odds } & \mathrm{p} \\
\text { ratio } & \text { value }^{\dagger}\end{array}$ & $\begin{array}{ll}\text { Odds } & \mathrm{p} \\
\text { ratio } & \text { value }^{\dagger}\end{array}$ & $\begin{array}{lc}\text { Odds } & p \\
\text { ratio } & \text { value }_{+}\end{array}$ & $\begin{array}{ll}\text { Odds } & \mathrm{p} \\
\text { ratio } & \text { value }^{\dagger}\end{array}$ \\
\hline
\end{tabular}

Contrasts between no rice bran added (NRB) and rice bran added (RB) formulations

$\begin{array}{lllllllll}\text { [NRB vs. RB] All } & \mathbf{5 . 8} & \mathbf{0 . 0 2 8} & 0.3 & \text { ns } & 2.9 & \text { ns } & \mathbf{5 . 3} & \mathbf{0 . 0 3 9} \\ \text { [NRB vs. RB] 100/0 } & \mathbf{2 . 9} & \mathbf{0 . 0 1 9} & 0.5 & \text { ns } & 2.1 & \text { ns } & 2.3 & \text { ns } \\ \text { [NRB vs. RB] 75/25 } & 0.9 & \text { ns } & 0.6 & \text { ns } & 0.5 & \text { ns } & 0.6 & \text { ns } \\ \text { [NRB vs. RB] } 50 / 50 & 2.3 & \text { ns } & 0.9 & \text { ns } & \mathbf{3 . 1} & \mathbf{0 . 0 1 7} & \mathbf{3 . 9} & \mathbf{0 . 0 0 4}\end{array}$

Contrasts among goat/beef percentages with the no rice bran added (NRB) formulations

$\begin{array}{lllllllll}{[100 / 0 \text { vs. } 75 / 25]} & \mathbf{2 . 7} & \mathbf{0 . 0 2 8} & 0.9 & \text { ns } & 2.5 & 0.050 & 1.9 & \text { ns } \\ {[100 / 0 \text { vs. } 50 / 50]} & 2.0 & \text { ns } & 0.7 & \text { ns } & 1.8 & \text { ns } & 1.4 & \text { ns } \\ {[75 / 25 \text { vs. } 50 / 50]} & 0.7 & \text { ns } & 0.8 & \text { ns } & 0.7 & \text { ns } & 0.7 & \text { ns }\end{array}$

Contrasts among goat/beef percentages with the rice bran added (RB) formulations

\begin{tabular}{lllllllll}
{$[100 / 0$ vs. $75 / 25]$} & 0.8 & ns & 1.4 & ns & 0.6 & ns & 0.5 & ns \\
{$[100 / 0$ vs. $50 / 50]$} & 1.6 & ns & 1.3 & ns & $\mathbf{2 . 7}$ & $\mathbf{0 . 0 3 9}$ & 2.5 & 0.050 \\
{$[75 / 25$ vs. $50 / 50]$} & 1.9 & ns & 0.9 & ns & $\mathbf{4 . 9}$ & $\mathbf{0 . 0 0 2}$ & $\mathbf{4 . 7}$ & $\mathbf{0 . 0 0 2}$ \\
\hline
\end{tabular}

\#Contrasts are tested by odds ratios for being in higher taste categories. The taste categories from highest to lowest are: 1) extremely pleasant, 2) moderately pleasant, 3) neither like-nor- 
dislike, 4) moderately unpleasant, 5) extremely unpleasant. The entity on the left-hand side of each contrast, shown in brackets, is the numerator for the odds ratio and the entity on the righthand side is the denominator. Therefore, an odds ratio of 5 indicates that the left-hand entry is 5 times more likely to be in the higher taste categories than the right-hand entry.

$\mathrm{NRB}=$ no rice bran added, $\mathrm{RB}=3 \%$ rice bran added; $100 / 0=100 \%$ goat meat, $75 / 25=75 \%$ goat meat $/ 25 \%$ beef, $50 / 50=50 \%$ goat meat $/ 50 \%$ beef.

${ }^{\dagger}$ Probability of a larger value of $\chi^{2}$.

\section{CONCLUSIONS:}

The NRB and RB sausage formulations with higher percentages of goat meat had higher concentrations of $\alpha$-tocopherol, $18: 2$ cis 9 trans 11 CLA, total n-3, total PUFA, total n-3/total n-6 ratio, and lower cholesterol concentration. The RB sausage formulations with higher percentages of goat meat had lower total Sat and an acceptable ratio of $(\mathrm{C} 18: 0+\mathrm{C} 18: 1)$ to C16:0. The NRB formulations with greater percentage of goat meat were more likely acceptable to the consumers than the RB formulations.

Abbreviations used: No rice bran, NRB; rice bran, RB; omega 3 fatty acid, n-3; omega 6 fatty acid, n-6; conjugated linoleic acid, CLA; United State Department of Agriculture, USDA; low density lipoprotein, LDL; United States Department of Agriculture Food Safety and Inspection Service, USDA/FSIS; Southern University Agricultural Research and Extension Center, SUAREC; American Official of Analytical Chemists, AOAC; butylated hydroxytoluene, BHT; Gas Chromatography/Mass Spectrophotometer, GC/MS; High Performance Liquid Chromatography, HPLC; diode array detector, DAD; monounsaturated fatty acids, MUFA; polyunsaturated fatty acids, PUFA; sum of saturated fatty acids, total Sat; desirable fatty acids, DFA; transvaccenic acid, TVA; sum of monounsaturated fatty acids, total MUFA; sum of polyunsaturated fatty acids, total PUFA; sum of omega 3 fatty acids, total n-3; sum of omega 6 fatty acids, total $\mathrm{n}-6$; ratio of sum of omega 3 to sum of omega 6 , total n-3/total n-6; micrometer, $\mu \mathrm{m}$; milliliter, $\mathrm{mL}$; microliter, $\mu \mathrm{L}$; millimeter, $\mathrm{mm}$; nanometer, $\mathrm{nm}$; wave length , $\lambda$; part per million, ppm; Celsius, ${ }^{\circ} \mathrm{C}$; minute , min; United Sates Department of Agriculture / National Institute of Food and Agriculture, USDA/NIFA

Competing interest: The authors declare that there is no conflict of interests regarding the publication of this paper.

Authors' contributions: All authors listed have contributed to this study that was conducted at Southern University Agricultural Research and Extension Center in Baton Rouge, Louisiana. The Email addresses for the authors are as follow:

Acknowledgments: This research was funded by USDA/NIFA Evans-Allen Grant no. 5621567. The authors thank Christopher Rogers, Sanjay Palle, Curtis Chisley, Albert Howard, and Shaina Craige for their assistance in carrying out the study. 


\section{REFERENCES:}

1. Zheng J S, Hu X.-J, Zhao, Y M, Yang J and Li D: Intake of fish and marine $\mathrm{n}-3$ polyunsaturated fatty acids and risk of breast cancer: meta-analysis of data from 21 independent prospective cohort studies. British Medical Journal. 2013, vol. 346, Article ID 13706. http://stateofobesity.org/adult-obesity/

2. Addrizzo J R: Use of goat milk and goat meat as therapeutic aids in cardiovascular diseases. Meat Goat Production Handbook. The Feasibility of Meat Goats in Minnesota, Agricultural Utilization Research Institute, Marshall, Minn, USA. 2002, 507- 537-7440 http://www.auri.org/.

3. Ehnholm C, Huttunen JK, and Pietinen P: Effect of diet on serum lipoproteins in a population with a high risk of coronary heart disease. New England Journal of Medicine. 1982, 307(14), 850-855.

4. U.S. Census Bureau, Statistical Abstract of the United States: United States Department of Agriculture (USDA), Agricultural Research Service, National Nutrient Database for Standard Reference Release 27. 2012.

5. United States Department of Agriculture (USDA), national Agricultural Library (NAL), National Nutrient Database (NDB) for Standards. http://ndb.nal.usda.gov/ndb/foods/show

6. Hu F B, Stampfer M J, Manson J E, Ascherio A, Colditz G A, Speizer F E: Dietary saturated fats and their food sources in relation to the risk of coronary heart disease in women. American Journal of Clinical Nutrition. 1999a, 70: 1001-1008.

7. Kelly FD, Sinclair S J, Mann NJ, Turner AH, Raffin FL, Blandford MV: Short-term diets enriched in stearic or palmitic acids do not alter plasma lipids, platelet aggregation or platelet activation status. European Journal of Clinical Nutrition. 2002, 56(6): 490-499.

8. Mensink RP, Zock PL, Kester AD and Katan MB: Effects of dietary fatty acids and carbohydrates on the ratio of serum total to HDL cholesterol and on serum lipids and apolipoproteins: A meta-analysis of 60 controlled trials. American Journal of Clinical Nutrition. 2003, 77(5):1146-1155.

9. Dawkins NL, Phelps O, McMillin KW and Forrester IT: Composition and physicochemical properties of Chevron patties containing oat bran. Journal of Food Science. 1999, 64(4):597-600.

10. Mahan L K, and Escott-Stump S: Krause's Food. Nutrition and Diet Therapy, W.B. Sanders, Philadelphia, Pa, USA. 1996, 59-61

11. Devendra C: Nutritional value of goat meat. International workshop on goat meat production in Asia. Tando Jam, Pakistan. 1988, March

12. James NA, Berry BW, Kotula AW, Lamikanra VT, and Ono, K: Physical separation and proximate analysis of raw and cooked cuts of chevron. In Proceedings of the 1990 International Goat Production Symposium. 1990, 22 October.

13. Banskalieva V, Sahlu T and Goetsch AL: Fatty acid composition of goat muscles and fat depots: a review. Small Ruminant Research. 2000, 37(3): 255-268.

14. National Agricultural Library (NAL) United States Department of Agriculture (USDA). National Nutrient Data base. 1989 http://www.nal.usda.gov/. 
15. Packaged Facts, Meat trends: culinary trends mapping report. Tech. Rep. LA182399, Market Research Group. 2007 Rockville, Md, USA.

16. Giugliano D: Dietary antioxidants for cardiovascular prevention. Journal of Nutrition Metabolism and Cardio Vascular Diseases. 2000, 10(1): 38-44.

17. Sugano M, and Tsuji E: Rice bran oil and cholesterol metabolism. Journal of Nutrition. 1997, 127(3): 5215-5245.

18. Saunders RM: Rice bran: composition and potential food sources. Food Review International. 1985, 1(3): 465-495.

19. Hegsted M, Windhauser MM, Lester SB and Morris SK: Stabilized rice bran and oat bran lower cholesterol in humans. Nutrition Research. 1993, 13(4): 387-398.

20. Nicolosi RJ, Ausman LM and Hegsted DM: Rice bran oil lowers serum total and low density lipoprotein cholesterol and apo B levels in nonhuman primates. Atherosclerosis. 1991, 88(2-3):133-142.

21. Gerhardt AL and Gallo NB: Full-fat rice bran and oat bran similarly reduce hypercholesterolemia in humans. Journal of Nutrition. 1998, 128(5): 865-869.

22. McDonald BE, Gerrard JM, Bruce VM and Corner E J: Comparison of the effect of canola oil and sunflower oil on plasma lipids and lipoproteins and on in vivo thromboxane A2 and prostacyclin production in healthy young men. The American Journal of Clinical Nutrition. 1989, 50: 1382-1388.

23. National Institute of Health (NIH): Celiac disease. NIH Publication. 2000, 08-4269 http://digestive.niddk.nih.gov/ddiseases pubs/celiac/celiac 508.pdf.

24. USDA/FSIS Directive: Safe and suitable ingredients used in the production of meat, poultry, and egg products. 2013, pp. 43 http://www.fsis.usda.gov/OPPDE/rdad/FSISDirectives/7120.1.pdf.

25. Prabhu G: Meat binding wonder. Stabilized rice bran brings function and savings to meat processing. Asia Food Journal. 2008, September, http://www.asiafoodjournal.com/article-5557-meatbindingwonder-asia.html.

26. Malekian F, Khachaturyan M, Gebrelul S and. Henson JF: Composition and fatty acid profile of goat meat sausages with added rice bran. International Journal of Food Science. 2014, Article ID 686298, 8 pages http://dx.doi.org/10.1155/2014/686298

27. Ramezanzadeh FM, Rao RM, Prinyawiwatkul W, Marshall WE and Windhauser M: Effects of microwave heat, packaging, and storage temperature on fatty acid and proximate compositions in rice bran. Journal of Agricultural and Food Chemistry. 2000, 48(2): 464-467.

28. AOAC International: Official Methods of Analysis. AOAC International. 1995, Washington, DC, USA.

29. Firestone D: Fatty acid composition by GLC, (marine oil), in Official Methods and Recommended Practices of the AOCS, Section Ce 1b-89. AOCS Press, Champagne, Ill, USA. $1993,4^{\text {th }}$ edition.

30. Katsanidis E, and Addis P B: Novel HPLC analysis of tocopherols, tocotrienols, and cholesterol in tissue. Free Radical Biology and Medicine. 1999, 27(11-12):1137-1140. 
31. Peryam DR and Pilgrim EJ: Hedonic scale method of measuring food preferences. Food Technology. 1957, 11:9-14.

32. SAS: SASUser's Guide. 2004, 12. 3.SAS Institute, Cary, NC, USA,

33. Malekian F, Rao MR, Prinyawiwatkul W, Marshall W E, Windhauser MM and Ahmedna M: Lipase and lipoxygenase activity, functionality, and nutrient losses in rice bran during storage. 2000, Bulletin Number 870, Louisiana State University Agricultural Center.

34. Whetsell M S, Rayburn EB, and Lozier J D: Human health effect of fatty acids in beef. Fact sheet for project "Pasture- Based System for Appalachia" West Virginia University and U.S. Department of Agriculture's Agricultural Research Service, and Virginia Tech. 2003, August https://www.wvu.edu/ agexten/forglvst/humanhealth.pdf

35. Judd J T, Baer D J, Clevidence B A, Kris-Etherton P, Muesing R A and Iwane M: Dietary cis and trans monounsaturated and saturated FA and plasma lipids and lipoproteins in men. Lipids. 2002, 37(2): 123-131.

36. Willet W C: The scientific basis for TFA regulation - is it sufficient? In Proceedings of the first international symposium on "Trans fatty acids and health", Rungstedgaard, Denmark. 2005, 11-13 September, p. 24.

37. Nigel S, Hocquette JF, Nuernberg K, Dannenberger D, Richardson I, and Moloney A: Review: Innovations in beef production systems that enhance the nutritional and health value of beef lipids and their relationship with meat quality. Journal of Meat Science. 2006, 74:17-33.

38. Kramer KG, Sehat N, Dugan MER, Mossoba MM, Yurawec MP, Roach JG, Eulitz K, Aalhus JL, Schaefer AL and Ku Y: Distribution of conjugated linoleic acid (CLA) isomers in tissue lipid classes of pigs fed a commercial CLA mixture by gas chromatography and silver ion-high-performance liquid chromatography. Lipids. 1998, 33: 549-558.

39. Dannenberger D, Nuernberg K, Nuernberg G, Scollan N, Steinhart H, and Ender K: Effects of pasture vs. concentrate diet on CLA isomer distribution in different tissue lipids of beef cattle. Lipids. 2005, 40: 589-598.

40. Belury MA: Conjugated linoleic acids in type 2 diabetes mellitus: implications and potential mechanisms. In Sebedio J L, Christie WW and Adlof RO (Eds.) Advances in conjugated linoleic acid research. Champaign, IL: AOCS Press. 2003, 2: 267-281.

41. Kepler C R, Hirons KP, McNeill JJ and Tove SB.: Intermediates and products of the bio hydrogenation of linoleic acid by Butyrivibrio fibrisolvens. Journal of Biological Chemistry. 1966, 241: 1350.

42. Larsen TM, Toubro S, Astrup A: Efficacy and safety of dietary supplements containing CLA for the treatment of obesity evidence from animal and human studies The Journal of Lipid Research. December 2003, 44, 2234-2241.

43. Webb EC and O'Neill HA: The animal fat paradox and meat quality. Journal of Meat Science. 2008, 80:28-36

44. Zigoneanu IG, Williams L, Xu, and Sabliov,C M. : Determination of antioxidant components in rice bran oil extracted by microwave-assisted method. Bio-resource Technology. 2008, 99(11): 4910-4918. 
45. Sabliov C M, Fronczek C, Astete C E, Khachaturyan M, Khachatryan L and Leonardi C: Effect of temperature and UV light degradation of $\alpha$-tocopherol in free and dissolved form. Journal of the American Oil Chemists Society. 2009, 86(9): 895-902.

46. McMillian KW and Brock AP: Production practices and processing for value-added goat meat. Journal of Animal Science. 2005, 83:E57-E68.

47. James NA, and Berry BW: Use of chevon in the development of low-fat meat products. Journal of Animal Science. 1997, 75:571-577.

48. Cosenza GH, Williams SK, Johnson DD, Sims C, and McGowan CH: Development and evaluation of a smoked sausage product. Journal of Meat Science. 2003, 64:119-124.

49. Dawkins NL, Gager J, Cornillon JP, Kim Y, Howard H, and Phelps O: Comparative studies on the physicochemical properties and hydration behavior of oat gum and oatrim in meat-based patties. Journal of Food Chemistry and Toxicology. 2001, 66(9):12761282.

50. Bratcher CL, Dawkins NL, Solaiman S, Kerth CR, and Bartlett JR: Texture and acceptability of goat meat frankfurters processed with 3 different sources of fat. Journal of Animal Science. 2010, 89:1429-1433. 